\title{
EDITORIAL
}

For reprint orders, please contact: reprints@futuremedicine.com

\section{Hepatitis E virus-associated neuropathy: an emerging extrahepatic manifestation}

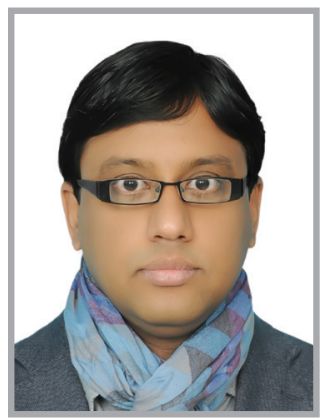

Mohammad Khalid Parvez*

“...clinicians should strongly consider the

possibility of hepatitis E infection in patients

with neurologic disorders, especially in

peripheral nerve and liver complications."
Hepatitis E virus virus (HEV), the causative agent of hepatitis $\mathrm{E}$, is an important public health issue, having water-borne, food-borne and zoonotic modes of transmission [1]. Hepatitis E infection may be symptomatic or asymptomatic, with a global mortality rate of approximately $2 \%$, including cases of fulminant liver failure in pregnant women in developing nations [2]. $\mathrm{HEV}$ is a nonenveloped, plus-sense RNA virus that has four recognized genotypes, 1, 2, 3 and 4, which are infectious to humans. Of these, genotypes 1 and 2 are mainly restricted to humans and nonhuman primates, whereas genotypes 3 and 4 are infectious to swine, deer, boar and few other mammals in addition to humans [1]. While genotype 1 circulates in Asia, including the Middle East, genotype 2 is prevalent in African and Latin-American countries. By contrast, genotypes 3 and 4 are mainly confined to Eastern Asian countries, Eastern and Western Europe, and North America. Although HEV generally causes self-limiting acute infection, chronic cases of autochthonous hepatitis $\mathrm{E}$ in clinically immunocompromised patients has also emerged in high-income industrialized nations [3]. Most of these autochthonous-sporadic cases have been attributed to genotype 3 and 4, and a zoonotic association with the consumption of pork, deer and wild boar meat has been established [4].

\section{Extrahepatic manifestation of HEV}

HEV is inherently a hepatotropic virus. However, it is unclear how the virus reaches the liver and, therefore, an extrahepatic site(s) of replication is also possible. HEV replication has been demonstrated in the tonsils, small intestine, colon tissues and bile ducts of experimentally as well as naturally infected pigs $[5,6]$. Furthermore, the HEV-associated extrahepatic manifestations have been reported in cases of kidney injury, hematological disorders and, most importantly, neurological complications. Notably, in hepatitis E patients, cases of neurologic signs and symptoms, such as Guillain-Barré syndrome (GBS), neuralgic amyotrophy and acute transverse myelitis, have been widely reported from developing (five cases) as well as developed nations (13 cases) [7-19]. Although limited information on HEV-induced neurological manifestations are available, clinical cases of hepatitis E-associated GBS has received special attention across the world in recent years. Of note, the existing literature

\section{KEYWORDS}

- Guillain-Barré syndrome

- hepatitis E virus $\bullet H E V$ genotypes $\bullet$ neuropathy

"...it is unclear how the virus reaches the liver and, therefore, an extrahepatic site(s) of replication is also possible.” 
about HEV and neurologic symptoms is, however, mainly based on case reports or small case series, and there are no controlled trials/studies available to date.

\section{Guillain-Barré syndrome}

GBS is a rare, sporadically occurring disease that causes neuromuscular paralysis, with an annual incidence of 0.6-2.4/100,000 individuals worldwide $[20,21]$. GBS is defined as an acute inflammatory demyelinating polyradiculoneuropathy presenting, in its classical form, as a rapidly evolving symmetric and ascending motor paralysis with hypotonia and areflexia accompanied by an acellular cerebrospinal fluid response [22]. Symptoms of GBS typically peak within 4 weeks and then plateau before resolving. More than $50 \%$ of GBS patients experience severe pain and autonomic symptoms, such as cardiac arrhythmias, blood pressure instability or urinary retention. Of these, approximately $20 \%$ of patients continue to have severe disease despite treatment, and approximately $5 \%$ die of the syndrome.

\section{Underlying mechanism(s)}

In approximately $60 \%$ of cases, GBS is preceded by infections with bacterial agents (Campylobacter jejuni, Haemophilus influenza and Mycoplasma pneumoniae), as well as viruses from the Herpesviridae family (cytomegalovirus, varicella zoster virus and Epstein-Barr virus) [23]. Although uncommon, hepatitis viruses, such as $\mathrm{HAV}, \mathrm{HBV}$ and $\mathrm{HCV}$, have also been reported to be GBS-triggering agents [24]. Clinical evidence suggests that GBS is an organspecific, immune-mediated disorder caused by synergistic interaction of cell-mediated and

"Although uncommon, hepatitis viruses, such as $\mathrm{HAV}$, HBV and HCV, have also been reported to be Guillain-Barré syndrome-triggering agents." humoral immune responses targeting peripheral nerve antigens. However, the molecular or cellular mechanism(s) by which infection can trigger GBS is not completely understood. It is thought that the immune system mistakenly attacks myelin or axons by a molecular mimicry mechanism. It has been postulated that infected cells can produce ganglioside (GM1, GM2, GD1B and GQ1B)-like self-antigenic epitopes, which elicit the production of antiganglioside antibodies that may disrupt the molecular topography of nodal and paranodal proteins, and thus induce motor axonal degeneration $[25,26]$. The implication of anti-GM2 antibody in the pathogenesis of cytomegalovirus-induced GBS has been described [26]. However, for GBS related to hepatitis A, B and C, no homologous epitopes to components of the peripheral nerves have been described to date. Of note, very recently, the first description of the presence of anti-GM2 and anti-GM1 antibodies in HEV-induced GBS cases have been reported $[13,16]$.

\section{Challenges to diagnosis \& treatment}

Diagnosis of GBS is based on clinical features, cerebrospinal fluid testing and nerve conduction studies. Although there is no specific drug for GBS, most patients have good outcomes without sequelae after conventional plasma exchange and intravenous immunoglobulin therapy. Moreover, the proper and timely diagnosis of $\mathrm{HEV}$ infection in general and in neurological cases remains technically challenging. Lack of an approved algorithm, consistency of serologic tests and viral load quantification, in terms of sensitivity and specificity, are the limiting factors. Extrahepatic symptoms may develop not only during active $\mathrm{HEV}$ infection, but also after clearance of the virus, and therefore the association of such symptoms with hepatitis $\mathrm{E}$ is usually overseen in clinics and the morbidity burden remains underestimated. In a very recent report, GBS was shown to be associated with autochthonous HEV-genotype 3 infection in European patients $[16,17,19,27]$. In industrialized nations, the actual incidence of $\mathrm{HEV}$-associated GBS is unknown as autochthonous hepatitis $\mathrm{E}$ remains underdiagnosed. This is in part due to the fact that HEV infection is frequently subclinical, and because the neurological findings surpass liver injuries and hepatitis is not suspected. In the majority of such cases, HEV RNA is normally found only up to 4-6 weeks after onset of clinical symptoms. Therefore, the problem is that, if the onset of neurological symptoms is often $>4-8$ weeks after viral infection, serology is the only diagnostic tool. The hepatitis E serology is further complicated in European cases where approximately $20-60 \%$ of individuals are HEV-IgG positive in which tests for HEV-IgM might be false positive due to immune cross-reactions or negative after a few months.

Although there is no established treatment for HEV infection, ribavirin is the commonly used regimen in chronic cases that has been proven successful in spontaneous clearance of serum HEV RNA [4]. In most of such cases, the patients were given no specific treatment and neurologic signs and symptoms resolved fully in 
3 months, and laboratory parameters returned to reference range within 6 months. However, a few were given intravenous immunoglobulin $(0.4 \mathrm{~g} / \mathrm{kg}$ once per day for 5 days $)$, which rapidly improved neurologic signs and symptoms, and progressively returned liver enzyme levels to reference limits within 4 weeks $[13,15,16]$. Nevertheless, the recently developed HEV vaccine [28] would be protective in naive travellers or in high-risk population groups, such as transplant recipients, and people with underlying liver conditions or neurological disorders.

\section{Conclusion $\&$ future perspective}

$\mathrm{HEV}$ infection in GBS patients is often associated with abnormal levels of liver enzymes. It is thus recommended that clinicians should strongly consider the possibility of hepatitis E infection in patients with neurologic disorders, especially in peripheral nerve and liver complications. HEV diagnosis may be suggested by examining the patient's serology, which should be further confirmed by viral RNA detection in the serum and/or CSF. Nonetheless, further investigations are needed to assess the actual prevalence of HEV infections in cases of neurologic disorders, especially those of unknown etiology. Since other tested drugs for GBS, including corticosteroids, have not proved beneficial, there is an obvious need for developing more acceptable and efficacious therapies.

\section{Acknowledgements}

The author expresses his gratitude to Dr S Jameel (Virology Group, International Centre for Genetic Engineering \& Biotechnology, New Delhi, India) for mentoring and supporting in the field.

\section{Financial \& competing interests disclosure}

The author has no relevant affiliations or financial involvement with any organization or entity with a financial interest in or financial conflict with the subject matter or materials discussed in the manuscript. This includes employment, consultancies, honoraria, stock ownership or options, expert testimony, grants or patents received or pending, or royalties.

No writing assistance was utilized in the production of this manuscript. “...the recently developed HEV vaccine would be protective in naive travellers or in high-risk population groups, such as transplant recipients, and people with underlying liver conditions or neurological disorders."

\section{References}

1 Yugo DM, Meng XJ. Hepatitis E virus: foodborne, waterborne and zoonotic transmission. Int. J. Environ. Res. Public Health 10, 4507-4533 (2013).

2 Purcell RH, Emerson SU. Hepatitis E: an emerging awareness of an old disease. J. Hepatol. 48, 494-503 (2008).

3 Parvez MK. Not so (a)cute: chronic evolution of hepatitis E virus. J. Gastroenterol. Hepatol. Res. 1, 84-85 (2012).

4 Parvez MK. Hepatitis E chronic infection: risks and controls. Intervirol. 56, 213-216(2013).

5 Williams TP, Kasorndorkbua C, Halbur PG et al. Evidence of extrahepatic sites of replication of the hepatitis $\mathrm{E}$ virus in a swine model. J. Clin. Microbiol. 39, 3040-3046 (2001).

6 Choi C, Chae C. Localization of swine hepatitis $\mathrm{E}$ virus in liver and extrahepatic tissues from naturally infected pigs by in situ hybridization. J. Hepatol. 38, 827-832 (2003).

7 Sood A, Midha V, Sood N. Guillain-Barré syndrome with acute hepatitis E. Am. J. Gastroenterol. 95, 3667-3668 (2000).

8 Kamani P, Baijal R, Amarapurkar D et al. Guillain-Barré syndrome associated with acute hepatitis E. Indian J. Gastroenterol. 24, 216 (2005).

9 Loly JP, Rikir E, Seivert M et al. GuillainBarré syndrome following hepatitis E. World J. Gastroenterol. 15, 1645-1647 (2009).

10 Fong F, Illahi M. Neuralgic amyotrophy associated with hepatitis E virus. Clin. Neurol. Neurosurg. 111, 193-195 (2009).

11 Mandal K, Chopra N. Acute transverse myelitis following hepatitis $\mathrm{E}$ virus infection. Indian Pediatr. 43, 365-366 (2006).

12 Cronin S, McNicholas R, Kavanagh E, Reid V, O’Rourke K. Anti-glycolipid GM2positive Guillain-Barré syndrome due to hepatitis E infection. Ir. J. Med. Sci. 180, 255-257 (2011).

13 Kamar N, Bendall RP, Peron JM et al. Hepatitis E virus and neurologic disorders. Emerg. Infect. Dis. 17, 173-179 (2011).

14 Kamar N, Weclawiak H, Guilbeau-Frugier $\mathrm{C}$ et al. Hepatitis $\mathrm{E}$ virus and the kidney in solid-organ transplant patients. Transplant 93, 617-623 (2012).

15 Santos L, Mesquita JR, Rocha PN et al. Acute hepatitis E complicated by GuillainBarré syndrome in Portugal, December 2012 - a case report. Euro. Surveill. 18 (2013).

16 Maurissen I, Jeurissen A, Strauven T, Sprengers D, De Schepper B. First case of anti-ganglioside GM1-positive GuillainBarré syndrome due to hepatitis $\mathrm{E}$ virus infection. Infection 40, 323-326 (2012).

17 Tse AC, Cheung RT, Ho SL, Chan KH. Guillain-Barré syndrome associated with acute hepatitis E infection. J. Clin. Neurosci. 19, 607-608 (2012).

18 Sharma B, Nagpal K, Sonnegowda RB, Praksh S. Hepatitis E with Guillain-Barré syndrome: still a rare association. $J$. Neurovirol. 19, 186-187 (2013).

19 Scharn N, Ganzenmueller T, Wenzel JJ et al. Guillain-Barré syndrome associated with autochthonous infection by hepatitis $\mathrm{E}$ virus subgenotype 3c. Infection doi:10.1007/ s15010-013-0448-5 (2013) (Epub ahead of print).

20 McGrogan A, Madle GC, Seaman HE, de Vries CS. The epidemiology of GuillainBarré syndrome worldwide. A systematic literature review. Neuroepidemiol. 32, 150-163 (2009).

21 Govoni V, Granieri E. Epidemiology of the Guillain-Barré syndrome. Curr. Opin. Neurol. 14, 605-613 (2001).

22 Lehmann HC, Hughes RA, Kieseier BC, Hartung HP. Recent developments and future directions in Guillain-Barré syndrome. J. Peripher. Nerv. Syst. 17, 57-70 (2012). 


\section{EDITORIAL Parvez}

23 Grygorczuk S, Zajkowska J, Kondrusik M et al. Guillain-Barré syndrome and its association with infectious factors. Neurol. Neurochir. Pol. 39, 230-236 (2005).

24 Kaida K, Sonoo M, Ogawa G et al. GM1/ GalNAc-GD1a complex: a target for pure motor Guillain-Barré syndrome. Neurology 71, 1683-1690 (2008).

25 Yu RK, Usuki S, Ariga T. Ganglioside molecular mimicry and its pathological roles in Guillain-Barré syndrome and related diseases. Infect. Immun. 74, 6517-6527 (2006).

26 Yuki N. Infectious origins of, and molecular mimicry in, Guillain-Barré and Fisher syndromes. Lancet Infect. Dis. 1, 29-37 (2001).

27 Rianthavorn P, Thongmee C, Limpaphayom $\mathrm{N}$ et al. The entire genome sequence of hepatitis E virus genotype 3 isolated from a patient with neuralgic amyotrophy. Scand. J. Infect. Dis. 42, 395-400 (2010).

28 Zhu FC, Zhang J, Zhang XF et al. Efficacy and safety of a recombinant hepatitis $\mathrm{E}$ vaccine in healthy adults: a large-scale, randomized, double-blind placebocontrolled, Phase 3 trial. Lancet 376 , 895-902 (2010). 